\title{
Propostas e lutas pela educação feminina: entre mães e operárias
}

\author{
Proposals and struggles for women's education: \\ between mothers and workers \\ Propuestas y luchas por la educación de las mujeres: \\ entre madres y trabajadoras
}

\author{
Maria Izilda Santos de Matos*
}

\begin{abstract}
Resumo: O artigo discute propostas em torno da educação feminina, observando como esta questão foi considerada estratégica para o aperfeiçoamento das mulheres, das famílias e das futuras gerações (finais do século XIX e início do XX). Focaliza duas perspectivas: uma primeira que envolveu projetos dirigidos para educação/ emancipação das mulheres de elites e setores médios urbanos e, outra, centrada na instrução/conscientização das operárias, particularmente, encaminhada pela professora socialista Ernestina Lesina.
\end{abstract}

Palavras-chave: educação feminina; mulher; Ernestina Lesina; emancipação feminina; operárias

Abstract: The paper discusses proposals on the female education, observing how this issue was considered strategic for the improvement of women, families and future generations (in the late nineteenth century and early twentieth). It focuses on two perspectives: the first involving projects aimed at education/emancipation of women from the elite and the middle class, and the second one involving the education/ consciousness of workers by the socialist teacher Ernestina Lesina.

Keywords: women's education; Ernestina Lesina; female emancipation; workers

\footnotetext{
* Doutora em História pela Universidade de São Paulo (USP), com Pós- Doutorado na Université Lumiere Lyon 2, Lyon/França. Pesquisadora 1 A do CNPq. Professora Titular da Pontifícia Universidade Católica de São Paulo (PPGH/PUC-SP, Brasil). Entre suas obras mais recentes, destacam-se: A cidade, a noite e o cronista: São Paulo de Adoniran Barbosa. (EDUSC, 2008); História e Deslocamentos: os portugueses (EDUSC; CEPESE, 2008); Portugueses: deslocamentos, experiências e cotidiano SP séculos $X I X$ e $X X$ (EDUSC, 2013). <mismatos@pucsp.br>.

$\mathrm{PhD}$ in History from the Universidade de São Paulo (USP), Maria Izilda Matos has developed a postdoctoral research at the Université Lumiere Lyon 2, Lyon / France. She is also researcher CNPq 1A and professor at the Pontífica Universidade Católica de São Paulo (PPGH/PUC-SP, Brazil). Her most recent works are: A cidade, a noite e o cronista: São Paulo de Adoniran Barbosa. (EDUSC, 2008); História e Deslocamentos: os portugueses (EDUSC, 2008); Portugueses: deslocamentos, experiências e cotidiano SP séculos XIX e XX (EDUSC, 2013).<mismatos@pucsp.br>.
} 
Resumen: El artículo analiza las propuestas para la educación de la mujer, observando cómo este tema fue considerado estratégico para el mejoramiento de las mujeres, las familias y las futuras generaciones (a finales del siglo XIX y principios del XX). Se centra en dos enfoques: el primero, de los proyectos destinados a la educación/ emancipación de las mujeres de clase media y la élite urbana; el otro centrado en la educación/concienciación de las trabajadoras, en particular, aquella presentada por la profesora socialista Ernestina Lesina.

Palabras clave: educación femenina; mujer; Ernestina Lesina; emancipación de las mujeres; trabajadoras

Toda mulher é uma escola, e é dela que as gerações recebem realmente a sua crença.

MiCHeLET, 1995, p. 3

Estes escritos buscam recuperar algumas propostas em torno da educação feminina entre os finais do século XIX e início do XX, observando como esta questão foi considerada estratégica para o aperfeiçoamento das mulheres, das famílias e das futuras gerações do país. Para tanto, destaca-se duas perspectivas: uma primeira que envolveu projetos dirigidos para educação/emancipação das mulheres de elites e setores médios urbanos e, outra, centrada na instrução/conscientização das operárias, particularmente, encaminhada pela professora socialista Ernestina Lesina e presentes no periódico Anima e Vita, criado e editado por ela.

\section{A luta pela educação feminina: propostas, periodismo e emancipação}

Emancipação moral da mulher é sua ilustração. Ilustração da mulher deve entender-se o verdadeiro conhecimento dos deveres que cada criatura tem para consigo mesma, e as subdivisões dos deveres da mulher: como filha, como esposa, como mãe, como ser formado pela obra imensa do progresso social (O Jornal das Senhoras, 1852, p. 3).

Na segunda metade do século XIX, o Brasil passou por um conjunto de transformações políticas, econômicas e sociais, destacando-se a abolição da escravidão (1888), o final da Monarquia com o advento da República (1889), o desenvolvimento capitalista e o movimento imigratório, somados à intensificação do processo de crescimento e 
intervenções urbanas. Estas alterações provocaram, num curto espaço de tempo e em ritmo acelerado, várias mudanças, cabendo destacar a maior presença feminina nos espaços públicos, uma maior circulação das mulheres nas cidades em percursos para o trabalho, a caminho das escolas ou em atividades de passeio e sociabilidade.

$\mathrm{O}$ regime republicano sob a influência da doutrina positivista e cientificista concentrou suas atenções no binômio família/cidade, que era visto como o sustentáculo de projetos normatizadores. As famílias foram estimuladas a desenvolver práticas que se adaptassem à modernidade, e neste sentido a educação tornou-se um ponto-chave, particularmente a feminina, pois através dela pretendia-se o aprimoramento físico e moral das mulheres e das crianças. Dessa forma, as reivindicações pela educação feminina se expandiram envolvendo diferentes agentes e cujas propostas foram polemizadas pela imprensa.

Desde meados do século XIX, apesar dos altos índices de analfabetismo, foram difundidos hábitos de leitura, dinamizando a maior circulação de periódicos, incluindo os direcionados às mulheres, que visavam a divulgação de novos produtos, valores e ideias, destacando-se a plataforma de luta pela educação feminina ${ }^{1}$.

O primeiro periódico dirigido e editado por mulheres foi o Jornal das Senhoras (1852-1855), de Joana Paulo Manso Noronha e Violante A. X. Bivar e Velasco, que apresentava sessões de moda, literatura, belas-artes e teatro, propunha mudança de atitudes e ideias, assumindo, sobretudo, "a luta pela emancipação moral da mulher por meio da educação" ${ }^{2}$. A emancipação não era identificada como autônima e independência econômica, mas, com a missão feminina de promover a evolução e o progresso da humanidade, para tanto a necessidade da instrução, que era reconhecida como fator de desenvolvimento social e civilidade para as mulheres.

Quando a maior parte dos pais de família procurarão dar educação as suas filhas, franca completa e liberal? Quando não se depreciarão as suas faculdades intelectuais e quando finalmente tentar-se-ão cultivar a sua inteligência, deixando que a liberdade de pensamento flutue em seus escritos.... Acredita só no que vos

\footnotetext{
${ }^{1}$ Entre os estudos sobre o periodismo feminino destacam-se: ALMEIDA, 1998; ARAS; MARINHO, 2012; BUITONI, 1990; BUITONI, 1981; DUARTE, 2003; ELEUTÉRIO, 2004; LIMA, 2007; MARTINS, 2001; MUZART, 2003; NASCIMENTO, 2007; PINTO, 2003.

${ }^{2}$ Joana Paulo Manso Noronha fazia uma crítica aos métodos educacionais da época, sugerindo que fossem abolidos os castigos físicos e que houvesse uma relação de amizade entre o mestre e os alunos. Além disso, defendia que as meninas pobres deveriam aprender não só prendas domésticas e religião, mas ter acesso a um ensino que as profissionalizasse (LIMA, 2012).
} 
digo - quando mais ilustrada for a mulher, melhor compreenderá os seus deveres, mais amplamente preencherá, essa missão sagrada de esposa e mãe; missão cujas bases principais são terna adesão, abnegação profunda, prudência, doçura e paciência ( $O$ Jornal das Senhoras, 1852, p. 3).

As publicações voltadas e produzidas por mulheres se expandiram, eram editadas em vários estados e circulavam por diferentes regiões, destacando-se $O$ Sexo Feminino (1873), Echo das Damas (1875-9), A Família (1888), A Mensageira (1897) O Domingo (1874), Jornal das Damas (1874), Myosotis (1875), A Voz Feminina (1900) e A Família (1888). Em sua maioria, estes periódicos introduziram reivindicações pelo direito à educação e reflexões sobre a condição feminina.

Uma mãe instruída, disciplinada, bem conhecedora dos seus deveres, marcará, fundo, indiscutivelmente, no espírito de seu filho, o sentimento da ordem, do estudo e do trabalho, de que tanto carecemos. Parece-me que são esses os elementos do progresso e da paz para as nações (ALMEIDA, 1897, p. 3).

As mulheres que editavam e escreviam nestas revistas, geralmente, pertenciam às elites ilustradas, identificavam o ler e escrever como um sinal de distinção social, elas se empenhavam em estimular hábitos de leitura, destacando a educação feminina como essencial para o casamento, criação dos filhos, vetor civilizatório familiar e até para a profissionalização (quando necessária). Buscando tornar as mulheres mais atuantes na esfera política, alguns periódicos incorporaram a luta pelo voto feminino.

A propagação do interesse pela educação encontrava-se envolta num "otiminismo pedagógico", sendo vista como indispensável para o aprimoramento da sociedade. A ampliação do acesso à instrução vinculava-se a crença que o novo regime multiplicaria a instituições escolares e expandiria o ensino público (humanista, democrático e progressista). Neste sentido, denunciavam-se carências, ineficiências e reivindicavam-se iniciativas competentes, já que o ensino público era restrito, enfrentava condições precárias como a falta de professores competentes e dedicados, salários baixos docentes, ausência de espaços apropriados e insuficiência de materiais didáticos (LOURO, 2000; VIDAL; HILSDORF, 2001; SÁ; SIQUEIRA, 2000).

Além dos periódicos femininos, a temática da educação tornou-se constante em círculos intelectuais, debates parlamentares e várias outras 
instâncias; a missão de polemizar e difundir propostas se fez presente na imprensa em geral, que apregoava a educação como meio de atingir o progresso e conduzir a sociedade à civilização. "A instrução este luzeiro que guia o nauta, na tempestuosa navegação pelo imenso oceano do tempo ao porto de salvação, é a bandeira imaculada que abriga á sua sombra os habitantes da cidade". (O Diário do Norte, 1877, p. 4)

Como a educação adquiriu cada vez mais importância ${ }^{3}$, a questão envolvia as famílias, instituições educacionais, poderes estabelecidos e instituições religiosas (particularmente católicas) visando ampliar o acesso e aperfeiçoar métodos e conteúdos. Aconselhava-se que os pais atentassem para seriedade do trabalho educacional, buscando matricular seus filhos(as) em estabelecimentos de conduta exemplar, que tivessem professores habilitados; desta forma, valorizou-se as instituições escolares, estimulando a abertura de novos colégios, particularmente, para as meninas ${ }^{4}$.

A principal finalidade das escolas era a preparação das meninas/ moças para a função de mãe e esposa, outras aptidões eram pouco valorizadas e até descartadas, assim, em alguns estabelecimentos reduzia-se a extensão e o número das matérias intelectuais. Os colégios femininos despendiam especial atenção para os currículos, além das disciplinas 'básicas' (Alfabetização, Gramática, Leitura, Caligrafia, Aritmética, Geografia, História Pátria e Universal) os programas incluíam economia e administração do lar, prendas domésticas (trabalhos manuais e de agulhas, corte e costura, lavar e passar roupa), conhecimentos de nutrição, culinária e serviço de copa, educação sanitária, higiene e puericultura, boas maneiras, etiqueta e comportamento social; algumas vezes, piano e música, rudimentos de Francês "se for vontade dos pais" (TRINDADE, 1996; LOURO, 1994; MORAIS, 1998).

Entre as várias escolas para meninas, havia algumas mantidas por leigos, contudo, as instituições religiosas (particularmente católicas) eram em número superior, nestas eram introduzidas noções de Doutrina

\footnotetext{
${ }^{3}$ No século XIX, o declínio do tamanho e da frequência dos dotes levou a valorização das qualidades pessoais e a educação da noiva passou a ser vista como um atrativo no novo pacto patrimonial, já que a auxiliaria a ser uma boa mãe, além de protegê-la contra as incertezas. Os homens da elite consideravam uma noiva alfabetizada mais atrativa que uma sem instrução, pois poderia ensinar os filhos a ler e escrever, sendo mais eficiente na administração da casa e controle dos criados (NAZZARI, 2001).

${ }^{4}$ Até o momento em foco, então o processo educativo se fazia através de preceptores particulares e aulas oferecidas regularmente na casa dos professores; foi nos primórdios da República que se expandiram e se institucionalizaram escolas religiosas e leigas, internatos e externatos femininos e masculinos (MARQUES, 2002; ALVES, 2003).
} 
Cristã e História Sagrada ${ }^{5}$. Apesar das polêmicas no início da República entre a laicidade e a reintrodução do ensino religioso obrigatório (ou pelo menos facultativo) nas escolas, os defensores do ensino religioso destacavam "não descuideis da educação de vossas filhas, Lembrai-vos de que só dentro das raias do Evangelho, podeis fazer sua felicidade". A formação cristã aproximava a mulher do "modelo mariano", tendo na figura da Virgem Maria um padrão de pureza, castidade, recato e pudor, exemplo de mãe carinhosa, devotada, abnegada, zelosa e modesta.

O processo educacional deveria interferir em comportamentos, até mesmo com a incorporação de posturas e gestos que consideravam ser mais 'apropriados', deste modo, se justificavam as ações disciplinares rígidas em relação ao corpo, posturas e modos vigiados, uso de uniforme, noções de etiqueta e elegância. Visando oferecer às alunas um aprimoramento físico e manutenção do corpo saudável, ensinavam cuidados corporais, atividades físicas (educação física) e higiênicas.

Constantemente, enfatizava-se a necessidade de cuidados educacionais e zelos especiais para com as meninas e moças, porque estas poderiam ser 'facilmente levadas' às futilidades, frivolidades e vaidade demasiada dispensando preocupação excessiva com a apresentação e aparência exterior (cuidados com a beleza, vestimentas e ornamentos), esquecendo-se dos valores interiores e morais. Também, regrava-se o ócio constante, leituras de determinados romances e distanciamento do exercício religioso, que eram considerados motivos que poderiam causar danos de formação dentro do modelo de feminilidade.

A moralidade das meninas e moças era outro motivo de preocupações, punindo as que não apresentassem os preceitos estabelecidos: recato, modéstia, submissão, integridade, refinamento de atitudes, disciplina e caráter. Estas preocupações deviam-se ao fato das mulheres serem vistas como 'pouco racionais', emotivas, sensíveis, impulsivas, não podendo ser 'plenamente responsáveis' pelos seus atos, por tanto seria necessário discipliná-las, evitando os descaminhos causados pelos descuidos com a instrução, a 'educação errada' ou a falta de uma 'esmerada educação'.

Propalava-se uma educação feminina baseada em valores como disciplina, aproveitamento adequado do tempo (pontualidade e assiduidade), noção de dever e responsabilidade, controle das emoções,

\footnotetext{
${ }^{5}$ A Igreja Católica, através de diferentes ordens masculinas e femininas, criou colégios internos e externatos destinados às filhas, das elites, com propostas educativas tradicionais e fortalecendo a instrução religiosa, preparando-as para o matrimônio e para a manutenção dos valores cristãos tradicionais (MANOEL, 1996).
} 
preceitos de ética, moral, ordem e economia, todos considerados indispensáveis para manter a felicidade e eficiência do lar ("o que a dona de casa economiza vale tanto quanto o marido ganha"). Baseado nos preceitos punição-premiação, o ensino buscava que as educandas adquirissem atitudes firmes, já que para o exercício das funções de mãe e esposa era preciso que fossem enérgicas, disciplinarizadoras, higiênicas, ordeiras, econômicas, laboriosas e prendadas.

As mulheres deveriam ser educadas para executar seus conhecimentos dentro dos lares, aonde exerceriam a sua "honrosa missão" - ser mãe, abnegada, responsável pela saúde e moral da família. A maternidade deveria ser assumida como um tributo, ser mãe requeria a subtração de suas vontades, desejos e sonhos que seriam compensados pela satisfação e felicidade dos filhos e, também do marido; assim, a maternidade foi transformada em função social sob a responsabilidade das mulheres, não somente na família, mais na própria pátria (as atividades escolares incluíam noções de patriotismo). Deste modo, a instrução adquiriu destaque, preparando e conscientizando as mulheres da importância da sua missão, podendo ser motivo de orgulho e felicidade, mas ainda, de culpa, já que as más atitudes e desvios de condutas dos filhos eram vistos como sinais de "falhas" maternais.

O ensino para os meninos das elites era direcionado para a preparação de ingresso nos cursos superiores, o título de bacharel era considerado garantia de reconhecimento intelectual, via de ascensão social, possibilidade de ocupação de cargos na burocracia e da carreira política. Já a instrução superior feminina era polêmica, alguns reforçavam que as mulheres possuíam condições para realizar cursos superiores, bastaria que tivessem oportunidade para se preparar; já outros apontavam as incompatibilidades entre a 'natureza' feminina e o desenvolvimento intelectual ('cabelos longos e ideias curtas'), alegavase que o excesso de instrução poderia interferir na saúde e capacidade reprodutiva das mulheres ${ }^{6}$.

A opção pela continuação dos estudos para as mulheres encontrou no magistério sua maior possibilidade, as escolas normais de formação

\footnotetext{
${ }^{6}$ No Brasil, o ingresso feminino nos cursos de ensino superior foi pouco expressivo, só a partir de 1879, que algumas instituições superiores permitiram a entrada de mulheres, embora só um pequeno número tenha ingressado, pois continuavam existindo dificuldades de admissão. A divulgação das excepcionalidades visava reforçar que as mulheres possuíam condições para tanto, desde que lhe fosse dado oportunidade de acesso. As conquistas femininas eram noticiadas, como de Dra Ermelinda de Sá (aprovada na Academia de Medicina do Rio de Janeiro), Dra. Myrthes de Campos formada em Direito e que enfrentou o Instituto dos Advogados para ter o direito de defender um réu, e só em 1900 foi consolidada a primeira matrícula feminina na Faculdade de Direito do Largo de São Francisco.
} 
de professores passaram a receber um número cada vez maior de moças. O magistério tornou-se uma atividade feminina, na medida em que passou a ser reputado como um campo por excelência de mulheres, ensinar era visto como uma extensão da função materna da educação, para a qual as mulheres tinham 'dons naturais': paciência, afetividade, capacidade de cuidar, educar, tratar e disciplinar crianças. Além do mais, esta atividade não 'distanciava' as mulheres dos lares, podendo ser exercida em meio período (PIZA, 1994).

O educar deixava de ser visto como uma profissão para se tornar um ato de delegação divina, colocado como 'alta' e 'importantíssima missão', envolvendo: trabalho árduo, dedicação cotidiana e difíceis situações. Assim, a escolha pelo magistério era colocada como especifica não podendo ser comparada a de outras profissões. Apregoava-se que o profissional reconhecesse que estava optando por uma entrega a causa nobre, e desta maneira, deveria se abster das preocupações salariais (MATOS; ALVES, 2005, p. 154).

Difundia-se que a educação era fundamental para a constituição de padrões ideais de feminilidade, com os quais as mulheres poderiam exercer com maior eficiência suas atribuições de esposa e mãe constituindo lares baseados na moralidade e contribuindo para a integridade da família. Considerava-se que a "nova mulher", a mulher instruída se constituiria num agente familiar, baluarte da moral e de valores que deveriam ser transmitidos aos filhos, assim, se tornavam agentes multiplicadores na difusão de conhecimentos e preceitos. De tal modo, a maternidade, além de "mandado biológico", adquiriu significado social, tornou-se uma função que "enaltecia e glorificava a mulher" como formadora dos futuros cidadãos e dos alicerces da pátria; os "sentimentos maternais" justificariam a dedicação á família e filhos, bem como a própria função de professora (ALMEIDA; BERNARDES; SANTOS, 1998. BERNARDES, 1989; BRUSCHINI; AMADO, 1988; ALMEIDA, 2000).

O advento da República e a difusão dos ideais positivistas reforçaram a identificação da família como a célula da sociedade, sendo o espaço doméstico reconhecido como palco de ação das mulheres, fazendo com que as responsabilidades femininas crescessem como mães, esposas e donas de casa, tendo como dever manter a casa em ordem, limpa, higienizada e aconchegante, enfim constituindo um lar harmônico e feliz. Destacando que a mulher tinha por natureza aptidões para os cuidados com a infância e era responsável pela família, ampliando 
seus poderes no universo da casa valorizando-a dentro do lar (rainha do lar), procurando fazer com que se reconhecessem nessa esfera e se esforçassem dentro da unidade familiar. Entretanto, ao se posicionar as mulheres no centro da família (ambiente privado) privilegiava-se espaço público para os homens (como locus do trabalho e da política)(MATOS, 2000; 2014).

A educação também foi uma via de "emancipação" e certas mulheres utilizaram desta brecha para conquistar novos espaços e exercer outras ocupações, a questão tornou-se um dos alicerces das pautas de reivindicação dos movimentos feministas, que consideravam que somente através da instrução as mulheres se conscientizariam da sua situação de subordinadas e poderiam se organizar, resistir e lutar contra a opressão e dominação a que estavam submetidas, rompendo barreiras e expandindo sua órbita de ação política (MATOS; ALVES, 2005).

As "feministas liberais" priorizam suas discussões e ações sobre a condição feminina nas elites e setores médios. As mulheres de outras origens sociais (pobres, operárias e populares) pareciam permanecer predestinadas à ignorância pelas próprias condições desfavoráveis de vida; entretanto, outras lutas foram desencadeadas em redutos populares e operários, novas práticas políticas (anarquistas e socialistas) levaram a frente propostas e ações pela educação e emancipação das mulheres (RAGO, 2007).

\section{A luta pela educação feminina: operárias, Anima e Vita e Ernestina Lesina}

Quem ousaria falar da missão da mulher no seio da família em frente de uma oficina que engole milhares e milhares de moças e de mulheres que os monstro capitalistas começam a dar as primeiras forças de crianças continuando, até cair extenuadas pela velhice prematura, aprisionadas durante dez e doze horas por dia, quase sem ter tempo de conhecer a família? A missão, destas infelizes é unicamente com seu trabalho embrutecedor, criar riquezas para os patrões. E' nestas condições que se tem a ousadia de falar da missão da mulher a desenvolver-se no seio da família? Quando constatamos que o matrimonio é objeto de divisão pelos mesmos que o defendem como instituição fundamental da nossa sociedade e considerado como um peso, ao qual, não se podendo evitar procuram adia-lo o mais possível? (LESINA, 1904, p. 5).

A expansão urbana de São Paulo esteve vinculada diretamente aos sucessos e/ou dificuldades da economia cafeeira; depois da chegada dos 
trilhos dos trens (1863) a capital paulista consolidou-se como centro capitalista, integrador regional, mercado distribuidor e receptor de produtos e serviços. A atração exercida pela cidade e a intensificação da imigração possibilitavam o crescimento demográfico concentrando um contingente de trabalhadores, enquanto uns dirigiam-se para a indústria, comércio, obras públicas e serviços, outros ficavam nas atividades por conta própria, temporárias e domiciliares, ocupações casuais, expedientes eventuais e incertos ${ }^{7}$.

As atividades industriais se implantaram e diversificaram, contando com a presença expressiva de estrangeiros na composição da mão de obra, que, em seus diferentes setores, se utilizavam do trabalho de mulheres e menores. Na fiação e tecelagem (algodão, seda, juta e lã), mulheres e meninas eram cerca de $70 \%$ do total dos empregados. No setor de vestuário, confecções de roupas, camisas, malharia, produção fabril de redes, fitas, bordados, tamancos, chapéus e alimentos (massas, biscoitos e chocolate), mais da metade dos trabalhadores eram mulheres, estas também atuavam na manufatura de cigarros, charutos e fumos, tocador, fósforos, velas e sabão. Pesava na opção por empregar mulheres a ideia bastante difundida da delicadeza para lidar com certos produtos, submissão, paciência, cuidado e docilidade eram atributos femininos ${ }^{8}$.

O emprego feminino fabril se caracterizou pela expressiva participação de imigrantes e preferencialmente de jovens, que recebiam um ordenado que representava apenas $65 \%$ do masculino adulto. $O$ cotidiano do trabalho era árduo, em ambientes insalubres, com jornadas extensas (11, 12 chegando a atingir 14 horas diárias), muitas vezes sem descanso semanal. Os baixos salários, as tarefas rotineiras, repetitivas, monótonas e menos qualificadas na hierarquia laboral foram determinantes do emprego maciço das mulheres nas indústrias.

Apesar das trabalhadoras serem vistas, inclusive pela imprensa operária, como pessoas "frágeis e indefesas", "passivas" e "carentes de consciência política", elas participaram ativamente das lutas operárias, atuaram em mobilizações, paralisaram as fábricas, tomaram parte em

\footnotetext{
${ }^{7} \mathrm{O}$ processo de crescimento urbano gerou novas oportunidades para as atividades comerciais e de abastecimento, multiplicaram-se os estabelecimentos de pequeno e médio porte como armazéns, açougues, adegas, quitandas, vendas, bares e botequins, também a possibilidade de comércio de rua, vários tipos de ambulantes, que vendiam verduras, legumes, frutas, flores, ovos, batatas, cebolas, aves, carnes, peixes, leite, pão, entre vários outros produtos, as mulheres se fizeram presentes nestas atividades. (MATOS, 2014)

${ }^{8}$ No ano de 1912, dos 10.204 operários recenseados pelo Departamento Estadual do Trabalho de São Paulo, 6.801 eram do sexo feminino. Boletim do DET/SP (1-2): 41 e 11 trimestre de 1911-12. p.76-77. (MATOS, 2005; MATOS; BORELLI, 2012)
} 
piquetes, reivindicando a redução da jornada e melhores condições de trabalho9. Por essa atuação, foram demitidas, taxadas de "indesejáveis", arroladas nas "listas negras" e acusadas de roubo, sabotagem ou boicote (MATOS, 2005; MATOS; BORELLI, 2012).

Neste contexto, cresceram as ações e organizações que visavam aparelhar e encaminhar ações organizativas do movimento dos trabalhadores (as) ${ }^{10}$. Os intensos fluxos de imigração e o processo de circularidade contribuíram para a difusão do ideário socialista (BIONDI, 2011; TRENTO, 1989; VIANNA, 2011) e anarquista, que contou com a participação de diversas mulheres: Maria Lacerda de Moura, Elvira Boni, Teresa Maria Carini, Isabel Cerruti, Maria Angelina Soares, Emma Ballerini, Sofia Garrido e Matilde Magrassi, algumas propunham um feminismo libertário (RAGO, 1985; 2007; PRACCHIA, 1994; RIBAS, 2011; MENDES, 2015; DOMINGOS, 2015; MENEZES NETO, 2015; KASSICK, 2015); entre as socialistas se destacou Ernestina Lesina ${ }^{11}$, que assumiu a defesa pela educação e conscientização da mulher trabalhadora.

A professora Ernestina Lesina ${ }^{12}$ escreveu em vários periódicos e em 1905 fundou o Anima e Vita, que visava propagar princípios socialistas e feministas. Este periódico contava com a colaboração de autores imigrados e estrangeiros ${ }^{13}$, havia a reprodução de poemas e de folhetins, a coluna fixa Fiori e Spine (Flor e Espinho) apresentava as notícias das ações operárias dentro e fora do país. Vários foram os temas abordados: alcoolismo, maternidade consciente, infância, família,

\footnotetext{
9 A imprensa operária representava a mulher de forma ambígua, ora como vítima da exploração do capitalismo e ora como heroína das lutas, como mãe e trabalhadora encarregada pela transformação da sociedade (MARTINS, 2006).

${ }^{10}$ Para a divulgação dos ideários anarquistas e socialistas, proliferou ampla imprensa operária, nesta se destacavam A Lanterna, La Battaglia, Germinal, La Barricata, A Plebe, A Terra Livre, Avanti!, O Amigo do Povo, O Chapeleiro, O Livre Pensador. Entre 1879 e 1927, circularam em São Paulo mais de 40 jornais na língua italiana, já periódicos em língua portuguesa que vinculados as lutas operárias, superavam o número de 70 (MARTINS, 2001; FERREIRA, 1978).

${ }^{11}$ Ernestina Lesina era italiana, professora, socialista, destacou-se na atuação político-partidária e dedicou-se à defesa das mulheres operárias, colaborou na imprensa anarquista e na socialista $(O$ Chapeleiro, A Voz do Trabalhador e O Livre Pensador), dirigiu o periódico Anima e Vita (1905). Além das suas ações pela imprensa operária, foi oradora em manifestações e fundou a Associação de Costureiras de Saco (1906) e a Comissão das Costureiras com o intuito de organizar a luta pelo aumento do preço pago pela costura, redução da jornada de trabalho e pela organização sindical, denunciando e colocando na pauta de discussões as péssimas condições de trabalho, maus-tratos, exploração e abuso sexual dos patrões; ela faleceu em São Paulo em 25/06/1909 (MATOS, 2005; GONÇALVES, 2013).

${ }^{12}$ Circulou semanalmente em São Paulo entre janeiro e junho de 1905, era escrito em italiano, alguns números se encontram disponíveis no Arquivo Edgard Leuenroth/UNICAMP.

${ }^{13}$ Vários artigos eram reproduções de textos já publicados em outros periódicos europeus, podendose observar que esta circularidade era uma forma de disseminação das ideias socialistas no Brasil, também presente em outros países com forte presença de imigrantes italianos.
} 
amor livre ${ }^{14}$, casamento, anticlericalismo e conflitos sociais. Através de um discurso marcadamente pedagógico, este periódico propunha-se a informar, educar, instruir e conscientizar as mulheres, questionando a "natureza biológica" da missão das mulheres na família.

Convinti invece della assoluta necessitá di organizzare in fascio le donne operaie a qualsiasi ramo d'industria esse appartengano, de fronte a tutta questa no facile, ma nuova e necessaria educazione da compiere, noi dobbiamo corredarsi di una forte dose di volontá e metterci seriamente al lavoro per la buona causa (LESINA, 1904, p. 5) ${ }^{15}$.

As propostas políticas de Ernestina visavam conscientizar as operárias do seu julgo, estimular a organização da luta pelos seus direitos e contra todas as formas de opressão. Para ela, a instrução das mulheres ampliaria a consciência social viabilizando a sua emancipação, destacava que os obstáculos à educação feminina eram meios de manter a alienação e reforçar modelos a serem seguidos.

Nas escolas públicas e particulares em que se dá, ou se pretende dar um complemento á instrução preliminar da mulher; também presente nas folhas literárias educativa... está os bons conselhos para a senhora de bem, que será a futura mãe de família; com os romances... feitos por escritoras e escritores corruptos e corruptores, para as famílias privilegiadas, onde se ensinam todos os melhores meios para conquistar um bom marido; em toda parte conversa-se da missão da mulher, e esta missão é a família (LESINA, 1904, p. 6).

Denunciava que a educação feminina encontrava-se sobre a órbita do controle do Estado e da Igreja, que buscavam restringir as mulheres dentro de um modelo, mantendo-as submissas e dóceis, assim, apontava que qualquer ação no sentido da politização feminina era considerada fatores de desestabilização social e desrespeito às "leis divinas". Neste sentido, se compreende o empenho na luta anticlerical presente nos escritos da professora e no Anima e Vita.

\footnotetext{
${ }^{14}$ Neste período, as proposta de amor livre centrava-se na crítica ao modelo de família burguesa e no casamento contratual, apregoando o direito a livre escolha do parceiro, o direito ao amor como um sentimento que definisse a união, que deveria ser constituída desvinculada das obrigações relativas ao Estado e à Igreja (RAGO, 1998).

${ }^{15}$ Tradução livre: "Convictos, em vez disso, da absoluta necessidade de organizar em facções/ agrupamentos as operárias de qualquer ramo da indústria a que se vinculem, diante dessa educação árdua, nova e necessária a levar a cabo, é preciso armarmo-nos de uma forte dose de vontade e pôr-nos seriamente ao trabalho da boa causa" (GONÇALVES, 2013).
} 
A mulher, geralmente, é supersticiosa... Da mulher do povo, cuja a primeira educação varia entre a ignorância e a palavra interesseira do sacerdote, á mulher burguesa, cuja educação e cultura está confiada a pessoas imbuídas do preconceito de ter de formar um ser privilegiado ou que viva fora da sociedade em que o homem vive, fora das lutas diárias da vida é todo um trabalho intenso que, talvez, inconscientemente, se realiza não para educar, mas para infundir na mulher a maior soma de preconceitos; conscientes talvez de que os indivíduos como os sexos tanto mais facilmente se dominam quanto menos têm o cérebro aberto á verdade, quanto menos sabem encarar a realidade das coisas julgando-as no seu verdadeiro valor, afora qualquer preconceito errado. E' de justiça reconhecer que nenhum esforço faz a sociedade para induzir a mulher para aceitar as reformas modernas de arte ou de sentimento e que ainda hoje, como no passado, se pretende arrasta-la, ensinar-lhe ainda uma vez a conjugar o verbo OBEDECER. A mulher, embora moldada ao meio em que uma educação errada e o egoísmo dos homens a têm encerrado, não estar satisfeita, e como doente que não tem mais força para gritar, silenciosamente se debate. Por isso tem medo, receia tudo o que é novo, e que não lhe é ensinado mas que é autoritariamente se pretende que aceite. Por isso guarda as suas antigas superstições, por isso ainda a mamãe diariamente ensina ao filho: 'Quem deixa a estrada antiga pela nova, esta enganado' (LESINA, 1904, p. 6).

Apontava como os preceitos da Igreja constituíam as bases de uma sociedade conservadora, hierarquizada, tradicional, antiliberal e antifeminista, persuadindo as mulheres à submissão, subserviência e obediência. Denunciava como a "mulher ignorante" era manipulada pela Igreja, que procurava mantê-la afastada da educação, subordinando-a, estabelecendo conformismo e resignação com a sociedade injusta e desigual.

$\mathrm{Na}$ sua luta anticlerical, Ernestina assinalava as incoerências e contradições praticadas, denunciando os vícios do clero: corrupção, luxúria e ganância, revelando as incongruências do sistema de educação hegemônico da igreja que tinham por base crença e superstição.

Qual é, então, a causa do efeito padre? Toda uma educação que a ciência e o progresso nos revelaram errada, que não correspondem á verdade. Com este grande erro foram educados os homens do passado; para tornar conhecido este grande erro, ainda hoje explorado por intrigantes, têm de trabalhar todos aqueles que sinceramente almejam dar uma melhor educação aos homens do futuro. Homens e jornais coletivamente combateram o padre, mestre de deturpação 
moral, revelando os escândalos e os vícios por eles praticados dentro das paredes do convento ou do seminário... Raciocinar sempre; este deve ser o trabalho constante do cérebro humano em condições normais. Moldar, então, a mente da criança ao dogma e, depois de adulto, joga-lo na vida onde tudo contrasta com o que lhe foi ensinado, é um verdadeiro crime moral e intelectual que se pratica em prejuízo das gerações vindouras... (LESINA, 1904, p. 6).

Para a professora socialista, a educação deveria distanciar-se das concepções religiosas que criavam obstáculos para despertar a consciência critica e a emancipação feminina. Em oposição ao ensino religioso autoritário e dogmático apregoava o ensino leigo, científico, racional e centrado em "princípio de liberdade", buscando a adesão e promulgando a convergência de esforços de sindicatos e associações operárias no sentido da alfabetização e educação dos trabalhadores(as), salientava que não bastava a educação escolar, deveria ser realizado um conjunto de ações sociais e culturais para instruir as mulheres.

O que se pode esperar da educação tradicional, senão que constitua indivíduos padronizados, dóceis e profundamente autoritários? É para isso que serve a escola burguesa: para fazer as pessoas aceitarem cegamente as normas estabelecidas, para incutir valores sociais e morais da classe dominante, para produzir e reproduzir indivíduos concebidos à sua imagem... gerações vindouras devem, pelo contrário, ser formadas de homens modernamente educados e preparados para a explicação da vida prática e bem endireitada que lhes dê sempre força de assumir a responsabilidade de suas ações. E negar-se-á a este resultado eliminando do ensino que prepara e amolda os cérebros humanos para as lutas do futuro, o 'credo quia absurdum', o ensino dogmático e religioso (LESINA, 1904, p. 6).

Junto com a crítica ao sistema de educação então em voga, a professora, apresentava sua proposta de educação feminina, pelo qual pretendia difundir o caráter político, rompendo com os preceitos restritivos de conservação da ordem social, desmascarando as estratégias de dominação, denunciando as injustiças, conscientizando e propondo transformações. Projetava que livre da ignorância, as mulheres instruídas poderiam romper com os códigos de controle, ampliar sua consciência política, ensinar melhor seus filhos, alcançar a emancipação de seus direitos sociais e políticos. Neste sentido, educação seria o ponto de partida para a superação dos preconceitos, o motor estratégico 
para emancipação de todos e para luta pela construção de uma nova sociedade ${ }^{16}$.

A proposta de Ernestina visava superar as barreiras entre trabalho manual e intelectual (integral), harmonizar as potencialidades humanas, difundir a liberdade de consciência e a igualdade social, levando ao desenvolvimento da consciência crítica das crianças e das mulheres, entendida como: melhor compreensão do seu papel social, capacidade de se autogovernar e de lutar pelos seus anseios, além de contribuir para transformação da realidade, já que cabiam as mulheres a função fundamental de educar as crianças (toda mãe deveria ser uma pedagoga) tornando-se agente de regeneração moral, influenciar nas transformações e na constituição de um futuro mais promissor.

O que se pode esperar da educação tradicional, senão que constitua indivíduos padronizados, dóceis e profundamente autoritários? É para isso que serve a escola burguesa: para fazer as pessoas aceitarem cegamente as normas estabelecidas, para incutir valores sociais e morais da classe dominante, para produzir e reproduzir indivíduos concebidos à sua imagem (LESINA, 1904, p. 6).

A operária no seu cotidiano era submetida às condições indignas no trabalho fabril, encontrando-se submissa aos patrões e desprestigiada pelos próprios trabalhadores, mas, encontraria na educação a possibilidade de suplantar a alienação e se emancipar. A nova mulher - a mulher instruída romperia com qualquer submissão e imposição dos pais, mestres, curas e patrões, tornando-se livre para ocupar novos espaços e buscar seus próprios caminhos. Para tanto se fazia importante difundir a educação baseada na liberdade, na livre expressão de pensar, na igualdade entre os sexos, constituída como proposta de ensino racional (em oposição ao dogmatismo da igreja que deveriam ser substituídos pelo método racional indicado pelas ciências naturais), antiautoritário e livre.

Nos mesmos banquinhos da escola, onde um princípio puramente ideal e dogmático infundiu durante tantos anos na mente humana

\footnotetext{
${ }^{16}$ Observa-se que várias das propostas de Ernestina convergem com a perspectiva da Escola Moderna baseada nos ensinamentos de Francisco Ferrer e que apareciam difundidas na imprensa operária e anarquista. A Escola Moderna propunha o desenvolvimento integral do educando com foco também na "educação informal", que possibilitaria variadas estratégias de intervenção pedagógica, assim, buscando despertar no trabalhador a consciência política, propunha-se a organização de bibliotecas populares, centros de estudos e de cultura, grupos de teatro e periódicos mensais, semanários e diários (RAGO, 1985).
} 
uma concepção errada; hoje que o livre pensamento emana em todas as manifestações da vida do homem; hoje que a sociedade toda combate para a conquista da verdade; hoje, pois, que a ciência e a natureza se nos revelam diariamente e auxiliam os homens na afanosa e nobre procura da verdade, acostuma-se a criança a conhecer de perto e diretamente o que se lhes ensina e que tem de formar o seu patrimônio intellectual. A coisa é menos difícil do que se pretende pelos adversários, pois o ensino que não somente desperta abstratamente a fantasia da criança, mas aprende com a observação dos fatos, torna-se para o pequeno aluno mais fácil e menos pesado... baseado nas leis da natureza que a ciência tirou do mistério, com os outros astros, evoluciona sem parar também e o sol destinado, não a ofender a vista do ignorante que, sem preparo, quer mira-lo, mas a aluminar os homens no caminho já empreendido da civilização e da sabedoria (LESINA, 1904, p. 6).

Apregoava uma educação que desenvolvesse o espírito crítico e liberdade criativa, considerava que a criança possuía aptidões naturais positivas e que o processo educativo deveria respeitar e desenvolver estas potencialidades e não reprimi-las através de imposições disciplinares punitivas e autoritárias. Deste modo, apontava para uma educação livre de dogmas e de preconceitos que estivesse embasada num ensino racional e integral, centrada na cooperação, confiança e respeito à liberdade, à individualidade e à expressão (GONÇALVES, 2013).

As propostas da socialista Ernestina Lesina, visavam desenvolver o espírito crítico e as ações de resistência das operárias, contestava os parâmetros tradicionais de educação, particularmente, a influência "nociva da igreja", fornecendo instrumentos para que as trabalhadoras se conscientizassem de sua condição, criassem estratégias de emancipação, resistissem e lutassem por seus direitos, buscassem por uma vida melhor e uma sociedade mais justa.

\section{Reflexões finais}

Desde os finais do século XIX que as propostas sobre a educação feminina entraram em pauta, sendo consideradas estratégicas para $\mathrm{o}$ aperfeiçoamento das mulheres e das famílias. Tanto os projetos dirigidos para as mulheres de elites e setores médios quanto para os indicados para as operárias viam a instrução um fator transformador para a constituição de uma "nova mulher".

Neste sentido, difundiu-se e consolidou-se um modelo de educação feminina para as elites que apregoou padrões ideais de feminilidade, 
que reforçaram as atribuições de esposa e mãe, valorizando as mulheres como o esteio da família, formadora dos futuros cidadãos e dos alicerces da pátria.

Entre as várias propostas de educação feminina que circulavam pela imprensa e no movimento operário, destacou-se a propagada pela socialista Ernestina Lesina, visando conscientizar/emancipar as trabalhadoras e estimular a luta por uma sociedade mais igualitária.

\section{Referências}

ALMEIDA, Ângela Maria de Oliveira; BERNARDES, Elizabeth Lannes; SANTOS, Maria de Fátima Souza Santos. Subordinação e rebeldia: o papel da mulher na família nuclear moderna. Revista Educação Pública, Cuiabá, v. 7, n. 11, p. 51-70, 1998.

ALMEIDA, Jane Soares de. As lutas femininas por educação, igualdade e cidadania. Revista Brasileira de Estudos Pedagógicos, Brasília, v. 81, n. 197, p. 5-15, 2000.

. Imagens de mulher: a imprensa educacional e feminina nas primeiras décadas do século. Revista Brasileira de Estudos Pedagógicos, Brasília, v. 79, n. 191, p. 31-41, 1998.

ALVES, Gislene. Cidade Educação e mulheres: Pindamonhangaba 1860-88. Dissertação (Mestrado em História) - Pontifícia Universidade Católica de São Paulo (PUC-SP), 2003.

ARAS, Lina Maria Brandão de; MARINHO, Simone Ramos. A imprensa feminina: normatização da conduta feminina nos jornais para mulheres (Bahia, 1860-1917). In: Historice, v. 3, n. 2, p. 96-115, 2012.

BERNARDES, Maria Thereza Caiuby C. Mulheres de ontem? Rio de Janeiro-século XIX. São Paulo: T.A Queiroz Editor, 1989.

BIONDI, Luigi. Classe e Nação: trabalhadores e socialistas italianos em São Paulo, 1890-1920. São Paulo: Editora da Unicamp, 2011.

BRUSCHINI, Maria Cristina; AMADO, Tina. Estudos sobre mulher e educação: algumas questões sobre o magistério. Cadernos de pesquisa, São Paulo, v. 64, p. 4-13, 1988.

BUITONI, Dulcília S. Imprensa feminina. São Paulo: Ática, 1990.

. Mulher de papel: a representação da mulher pela imprensa feminina brasileira. São Paulo: Loyola, 1981.

CRUZ, Heloísa de Faria. São Paulo em papel e tinta: periodismo e vida urbana1890-1915. São Paulo, EDUC/FAPESP/AESP/Imprensa Oficial de São Paulo, 2000.

DOMINGOS, Marília De Franceschi Neto. Ensino Religioso e Estado Laico: uma lição de tolerância. REVER, v. 9, n. 3, p. 45-70, 2009. Disponível em: <http://www.pucsp.br/ rever/rv3_2009/tdomingos.htm>. Acesso em: 10 maio 2015.

DUARTE, Constância Lima. Feminismo e literatura no Brasil. Revista Estudos Avançados da USP, v. 17, n. 49, 151-172, set./dez. 2003.

ELEUTÉRIO, Maria de Lourdes. O lugar da emancipação da mulher no periodismo paulista (1888-1930). Revista Iberoamericana, v. LXX, n. 208-209, p. 653-663, 2004. 
FERREIRA, Maria Nazaré. A Imprensa Operária no Brasil 1880-1920. Petrópolis: Vozes, 1978.

GONÇALVES, Caroline. Ernestina Lesina e o Anima Vita: trajetórias, escritos e luta das mulheres operárias. Dissertação de Mestrado (História) - Pontifícia Universidade Católica (PUC-SP), São Paulo, 2013.

HILSDORF, Maria Lúcia S. (Org.). Tópicos em história da educação. São Paulo: Edusp. 2001.

KASSICK, Clovis Nicanor. Pedagogia libertária na história da educação brasileira. Revista HISTEDBR, Campinas, n. 32, p. 136-149, dez. 2008. Disponível em: < http:// www.histedbr.fae.unicamp.br/revista/edicoes/32/art09_32.pdf>. Acesso em: 13 maio de 2015.

LIMA, Joelma V. O Jornal das Senhoras, um projeto pedagógico: mulher, educação, maternidade e corpo (RJ, segunda metade do século XIX). Tese (Doutorado em História) - Pontifícia Universidade Católica de São Paulo (PUC-SP), 2012.

LIMA, Sandra Lúcia Lopes. Imprensa feminina, revista feminina. Projeto História. Revista do Programa de Estudos Pós-Graduados de História, São Paulo, v. 35, n. 2, p. 221-240, dez. 2007.

LOURO, Guacira Lopes. Mulheres na sala de aula. In: DEL PRIORI, Mary (Org.). História das mulheres no Brasil. São Paulo: Contexto, 2000. p. 443-481.

. Uma leitura da história da educação sob a perspectiva do gênero. Revista

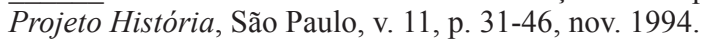

MANOEL, Ivan. A Igreja e educação feminina-1859-1919. Uma face do conservadorismo. São Paulo: Editora da UNESP, 1996.

MARQUES, Sandra Zilda S. A amiga da imperatriz, o olhar de Maria Graham sob o Brasil: 1821/1824. Dissertação de Mestrado. (História), Pontifícia Universidade de São Paulo (PUC-SP), 2002.

MARTINS, Ana Luiza. Imprensa: Práticas culturais em tempo de República, São Paulo (1890-1922). São Paulo: Editora da USP/FAPESP/Imprensa Oficial do Estado, 2001.

MARTINS, Angela Maria Roberti. Pelas Páginas Libertárias: Anarquismo, Imagens e Representações. Tese (Doutorado em História) - Pontifícia Universidade de São Paulo (PUC-SP), 2006.

MATOS, Maria Izilda Santos de. Cotidiano e Cultura: história, cidade e trabalho. 2. ed. Bauru: EDUSC, 2014.

. Em nome do engrandecimento da nação: representações de gênero no discurso médico - São Paulo 1890-1930. Revista Diálogos, DHI/UEUM, v. 4, n. 4, p. 77-92, 2000.

. Trama e Poder: um estudo sobre as indústrias de sacaria para o café (São Paulo 1888-1934). 6. ed. Rio de Janeiro: Sete Letras, 2005.

MATOS, Maria Izilda Santos de; BORELLI, Andrea. Espaço feminino no mercado de trabalho. In: PINSKY, Carla; PEDRO, Joana (Org.). Nova história das mulheres no Brasil, São Paulo: Contexto, 2012. p. 126-147.

MATOS, Maria Izilda Santos de; ALVES, Gisele. As mulheres: educação e progresso. Revista Mack-Arte, v. 6, p. 149-160, 2005. 
MENDES, Samanta Colhado. Anarquismo e Feminismo: as mulheres anarquistas em São Paulo na Primeira República (1889-1930). Disponível em: $<$ http://legacy.unifacef. com.br/novo/publicacoes/IIforum/SamantaColhadoMendes.pdf>. Acesso em: 12 maio 2015.

MENEZES NETO, Antonio Julio de. Mariátegui e a fé na educação socialista. Disponível em: <http://www.5ebem.ufsc.br/trabalhos/eixo_05/e05a_t004.pdf>. Acesso em: 15 maio 2015.

MICHELET, Jules. A mulher. São Paulo: Martins Fontes, 1995.

MORAES, Carmen Sylvia Vidigal; CALSAVARA, Tatiana; MARTINS, Ana Paula. O ensino libertário e a relação entre trabalho e educação: algumas reflexões. 33a Reunião Anual da ANPED, 2010, Disponível em: <http://www.scielo.br/pdf/ep/2012nahead/ aop638.pdf>. Acesso em: 16 maio 2015.

MORAIS, Maria Arisnete Câmara de. A leitura de romances no século XIX. Cadernos CEDES, Campinas, v. 19, n. 45, p. 71-85, jul. 1998.

MUZART, Z. L. Uma espiada na imprensa das mulheres no século XIX. Revista de Estudos Feministas, Florianópolis, v. 11, n. 1, p. 225-233, jan./jun. 2003.

NASCIMENTO, Cecília Vieira do; OLIVEIRA, Bernardo J. O Sexo Feminino em campanha pela emancipação da mulher. Cadernos Pagu, n. 29, p. 429-457, jul./dez. 2007.

NAZZARI, Muriel. O desaparecimento do Dote. Mulheres, famílias e mudança social em São Paulo, Brasil, 1600-1900. São Paulo: Cia das Letras. 2001.

PINTO, Céli Regina. Uma história do feminismo no Brasil. São Paulo: Fundação Perseu Abramo, 2003.

PIZA, Edith. Contaminação de práticas no trabalho de magistério: notas para reflexão. Revista Projeto História, São Paulo, n. 11, p. 79-89, nov. 1994.

PRACCHIA, Lygia. Os libertários e os caminhos da emancipação feminina. Projeto História, v. 11, 1994.

RAGO, Margareth. Do cabaré ao lar: a Utopia da cidade disciplinar. São Paulo: Paz e Terra, 1985.

Do Amor Libertário. Libertárias - Revista de Cultura Libertária. São Paulo, n. 10, p. 11-12, 10 set. 1998.

. Adeus ao feminismo? Feminismo e (pós) modernidade no Brasil. Cadernos

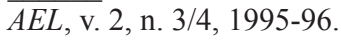

. Relações de Gênero e Classe Operária no Brasil, 1890-1930. In: MELO, Hildete Pereira de; PISCITELLI, Adriana; MALUF, Sônia Weidner; PUGA, Vera Lúcia (Org). Olhares feministas. Brasília: Ministério da Educação/Unesco, 2007. p. 219-238.

RIBAS, Ana Claudia. A insustentável leveza da liberdade: um breve olhar sobre os discursos referentes ao amor livre nas publicações anarquistas do século XX. Anais do I Seminário Internacional História do Tempo Presente. Florianópolis, 2011. p. 20332041.

SÁ, Nicamor Palhares; SIQUEIRA, Elizabeth Madureira. Co-educação, gênero e direitos civis. III Congresso Luso-Brasileiro da Educação, Coimbra, Portugal, 2000.

TRENTO, Angelo. Do outro lado do Atlântico: um século de imigração italiana no Brasil. São Paulo: Nobel, 1989. 
TRINDADE, Etelvina Maria. Clotildes e Marias: mulheres de Curitiba na Primeira República. Curitiba: Farol do Saber, 1996.

VIANNA, Marly de Almeida Gomes. Ideias Socialistas no Brasil através da Imprensa. Anais do XXVI Simpósio Nacional de História - ANPUH. São Paulo, julho 2011. Disponível em: <http://www.snh2011.anpuh.org/resources/anais/14/1300117978.pdf>. Acesso em: 20 maio 2015.

VIDAL, Diana Gonçalves. HILSDORF, Maria Lúcia Spedo. (Org.). Tópicos em história da educação. São Paulo: Edusp, 2001.

\section{Fontes:}

ALMEIDA, Júlia Lopes. A Mensageira. Edição fac-similar. 2 v. São Paulo, Imprensa Oficial do Estado de São Paulo, 1897. p. 3.

Anima e Vita, São Paulo, anno I, n. 13. p. 1, 26 mar. 1905.

Homens de lettras de Pindamonhangaba. O Diário do Norte, Pindamonhangaba, 31 jun. 1877. Editorial, p. 1.

LESINA, Ernestina. O ensino leigo. O Livre Pensador, São Paulo, 10 jul. 1904, n. 39.

LESINA, Ernestina. O Livre Pensador. São Paulo, 16 out. 1904. n. 52.

LESINA, Ernestina. Superstição da mulher. O Livre Pensador, São Paulo, 12 jul. 1904, n. 35 .

O Jornal das Senhoras, Rio de Janeiro, 20 ago. 1852.

O Jornal das Senhoras, Rio de Janeiro, 25 jan. 1852.

Recebido: 05 de outubro de 2015 Aprovado: 04 de dezembro de 2015 